\title{
Multiple cause-of-death data among people with AIDS in Italy: a nationwide cross-sectional study
}

\author{
Enrico Grande ${ }^{1}$, Antonella Zucchetto², Barbara Suligoi ${ }^{3}$, Francesco Grippo ${ }^{1}$, Marilena Pappagallo', Saverio Virdone ${ }^{2}$, \\ Laura Camoni ${ }^{3}$, Martina Taborelli², Vincenza Regine ${ }^{3}$, Diego Serraino ${ }^{2^{*}}$ and Luisa Frova ${ }^{1}$
}

\begin{abstract}
Background: Multiple cause-of-death (MCOD) data allow analyzing the contribution to mortality of conditions reported on the death certificate that are not selected as the underlying cause of death. Using MCOD data, this study aimed to fully describe the cause-specific mortality of people with AIDS (PWA) compared to people without AIDS.

Methods: We conducted a nationwide investigation based on death certificates of 2,515 Italian PWA and 123,224 people without AIDS who had died between 2006 and 2010. The conditions most frequently associated with PWA mortality, compared to people without AIDS, were identified using an age-standardized proportion ratio (ASPR) calculated as the ratio between the age-standardized proportion of a specific cause among PWA and the same proportion among people without AIDS.
\end{abstract}

Results: The most frequently reported conditions at death among PWA were infectious/parasitic diseases (52\%), digestive (36\%), respiratory (33\%), and circulatory (32\%) system diseases, and neoplasms (29\%). All AIDS-defining conditions resulted highly associated (ASPR significantly greater than unity) with PWA deaths. Significant associations also emerged for leishmaniasis (ASPR = 188.0), encephalitis/myelitis/encephalomyelitis (ASPR =14.3), dementia (ASPR =13.1), chronic viral hepatitis (ASPR = 13.1), liver fibrosis/cirrhosis (ASPR = 4.4), pneumonia (ASPR $=4.4)$, anal $(A S P R=12.1)$ and liver $(A S P R=1.9)$ cancers, and Hodgkin's disease (ASPR $=3.1$ ).

Conclusions: Study findings identified the contribution of several non-AIDS-defining conditions on PWA mortality, emphasizing the need of preventive public health interventions targeting this population.

Keywords: HIV/AIDS, Cause-specific mortality, Multiple causes of death, Italy

\section{Background}

In Italy, about 4,000 new HIV diagnoses and approximately 800 AIDS cases are reported yearly to the National HIV and AIDS surveillance systems, with a steady trend observed in the last decade. However, the distribution of new AIDS cases by transmission mode has changed over time, with a decreasing proportion of injecting drug users (31.2\% in 2005 and $11.3 \%$ in 2015) and an increasing proportion of cases acquired through sexual contact $(61.3 \%$ in 2005 and $79.8 \%$ in 2015) [1]. A total of $123,000(115,000-145,000)$ individuals aged

\footnotetext{
*Correspondence: serrainod@cro.it

${ }^{2}$ Unit of Cancer Epidemiology, CRO Aviano National Cancer Institute, Via

Gallini 2, 33081 Aviano, PN, Italy

Full list of author information is available at the end of the article
}

15 years or more were estimated to be living with HIV in Italy at the end of 2012 with a prevalence of 0.28 (0.24-0.32) per 100,000 residents [2]. In the same year, 94,146 people diagnosed with HIV and referred to the national healthcare system were reported. The majority were males $(70.1 \%)$, Italians $(84.4 \%)$, and aged between 25 and 49 years $(63.4 \%)$; the probable route of transmission was heterosexual contact in $37.5 \%$ of cases, injecting drug use in $28.1 \%$, and male-to-male contact in $27.9 \% ; 87.6 \%$ underwent highly active antiretroviral therapy (HAART) [3]. HAART introduction in the mid1990s has led to marked improvements in survival of HIV-infected people [4] with consequent changes in mortality patterns. In particular, a growing proportion of 
deaths due to non-HIV/AIDS-related causes [5-8] has emerged over time.

The analysis of mortality by cause mainly refers to the underlying cause of death (UC), defined as the disease or injury that initiated the train of morbid events leading directly to death, or the circumstance of the accident or violence that produced the fatal injury [9]. However, the $\mathrm{UC}$ approach is often insufficient to properly analyze mortality, as it captures only the "tip of the iceberg." In fact, it could divert the attention from conditions that tend to be reported as contributory causes. As a consequence, the contribution of these conditions to overall mortality could be underestimated [10-12].

On the other hand, the use of multiple cause-of-death (MCOD) data - i.e., all the diseases that the certifying physician has considered relevant to death - allow analyzing all the medical circumstances surrounding the death and enable a more exhaustive description of the cause-specific mortality patterns [13]. This is important for the whole population, but especially for specific subgroups characterized by elevated co-morbidity, such as people with AIDS (PWA). Despite the increasing availability of MCOD data in many countries and the growing number of studies focusing on MCOD, only few have taken into consideration people with HIV infection or AIDS $[6,14,15]$.

This study aimed to comprehensively describe the mortality patterns of Italian PWA using MCOD data. Furthermore, it aimed to identify the specific conditions that are most frequently associated with PWA mortality, as compared to people without AIDS.

\section{Methods}

This population-based, cross-sectional investigation compared the death certificates of PWA with those of people without AIDS, for the years 2006 to 2010. The two groups of death certificates were identified by linking two nationwide data sources: the Italian National AIDS Registry (RAIDS) and the National Register of Causes of Death (RCOD).

\section{Sources of data}

The RCOD, managed by the Italian National Institute of Statistics (ISTAT), collects all death certificates issued in Italy. Individual death certificates consist of two sections: a medical section for certification of causes of death reported by a physician and a sociodemographic section filled in by local civil registration officers. Sociodemographic information refers to sex, age, place (municipality or foreign state) of birth, residence and place of death, citizenship, and education level. The cause-of-death certification includes the description of the sequence of conditions that directly lead to death and, where appropriate, other conditions that may have contributed but were not directly linked to death. The classification of causes of death and the selection of the UC is performed according to the rules and provisions included in the International Classification of Diseases, $10^{\text {th }}$ Revision (ICD-10) provided and updated by the World Health Organization (WHO). In recent years, ISTAT also disseminates MCOD data.

The RAIDS, managed by the National Institute of Health (ISS), collects information on PWA in Italy, according to the European AIDS case definition [16, 17]. The reporting of AIDS cases became mandatory in 1986. The RAIDS includes demographic information on date of AIDS diagnosis, sex, age at diagnosis, place of birth and residence at diagnosis; conversely, date of death is not mandatorily updated. The RAIDS has a national coverage; a previous study estimated a $6 \%$ underreporting by linking RAIDS data with the National mortality database [18].

\section{Record-linkage and definition of the study groups}

In order to identify the death certificates referring to PWA, the RAIDS, updated to $31^{\text {st }}$ December 2010, was linked to the RCOD database for the period 2006-2010. The record-linkage was carried out in compliance with the national law regulating the use of data from PWA and according to the authorization of the Italian Data Protection Authority (provided in the National Statistical Plan).

The record-linkage was conducted using a semiautomated and validated procedure with an updated version of SALI software [19]. This is a deterministic matching procedure that relies on an automated multiplestep algorithm using blinded names, surnames, and date of birth as matching criteria. To optimize linkage sensitivity, SALI takes into account of most spelling errors; thus, subsequent manual comparison of other variables present in both databases (e.g., place of birth) is required to discard false-matched records. For the aims of the present study, two groups of deaths were identified through the record-linkage:

1) All the RCOD deaths matched to the RAIDS $(3,681)$, i.e., the deaths of PWA, representing the study group (AIDS deaths);

2) All the RCOD deaths non-matched to the RAIDS $(2,882,337)$, i.e., deaths of people without AIDS, further excluding deaths certificates with any mention of AIDS/HIV (ICD-10 codes B20-B24 and R75), representing the comparison group (non-AIDS/HIV deaths).

Furthermore, the following population subgroups were excluded from the analysis:

- Foreign citizens (295 death records among AIDS deaths, 26,623 death records among non-AIDS/HIV 
deaths), because of the linkage procedure lower sensitivity towards frequent spelling errors in foreign names/surnames and because of foreign citizens' higher propensity to migrate (which causes frequent losses to follow-up);

- Death certificates from Trento and Bolzano provinces (7 records among AIDS deaths, 42,412 records among non-AIDS/HIV deaths), for which MCOD were not available.

The present MCOD analysis focused on deaths occurred in the 35-54-year age class, where AIDS mortality rates were the highest, and which included $78 \%$ of total deaths among PWA in the period 2006-2010. The number of death certificates excluded from the comparison group due to the mention of B20-B24 or R75 codes was 1,905.

In the end, the study population included 2,515 records of AIDS deaths (among these, 486 death certificates had no mention of AIDS/HIV) and 123,224 records of nonAIDS/HIV deaths.

\section{Statistical analysis}

The conditions most frequently associated with PWA mortality were identified using an age-standardized relative risk indicator, which identifies the excess proportion of having a specific disease mentioned in the death certificate among PWA, as compared to those without AIDS/HIV.

For a specific cause of death $c$, the Age-Standardized Proportion Ratio (ASPR) was calculated as the ratio between the following estimated proportions:

1. $\hat{p}_{A c}$, proportion of death certificates mentioning the cause $c$ among AIDS deaths $(A)$;

2. $\hat{p}_{\bar{A} c}$, proportion of death certificates mentioning the cause $c$ among non-AIDS/HIV deaths $(\bar{A})$.

$$
\operatorname{ASPR}_{c}=\frac{\hat{p}_{A c}}{\hat{p}_{\bar{A} c}}
$$

The two estimated proportions were obtained through age standardization based on the 5-year age class distribution of total deaths aged 35-54 years, according to the following formulas:

$$
\begin{aligned}
& \hat{p}_{A c}=\sum_{x} \frac{{ }_{x} D_{A c}}{{ }_{x} D_{A}} \times{ }_{x} w \\
& \hat{p}_{\overline{A c}}=\sum_{x} \frac{{ }_{x} D_{\overline{A^{c}}}}{{ }_{x} D_{\bar{A}}} \times{ }_{x} w
\end{aligned}
$$

where:

$D_{A c}$ observed number of deaths certificates mentioning the cause $c$ among AIDS deaths
$D_{A}$ observed number of AIDS deaths

$D_{\bar{A} c}$ observed number of deaths certificates mentioning the cause $c$ among non-AIDS/HIV deaths

$D_{\bar{A}}$ observed number of non-AIDS/HIV deaths.

${ }_{x} w$ proportion of deaths at age $x\left({ }_{x} D\right)$ on the total number of deaths $(D)$.

The 95\% confidence intervals (CI) for the ASPR were calculated using the standard error formula for relative risks according to Altman [20]. ASPR significantly greater than unity indicates a higher frequency of a specific cause among AIDS deaths; conversely, values lower than unity indicate a higher frequency of the specific cause among non-AIDS/HIV deaths. Causes of death were analysed at a high level of specificity (ICD-10 category). Furthermore, the ASPR was calculated also for broad groups of causes (ICD-10 chapters).

\section{Results}

A comparison of UC and MCOD distribution between AIDS and non-AIDS/HIV deaths is presented in Fig. 1. The analysis of proportion of deaths by UC (Fig. 1a) provided evidence that AIDS deaths were mainly attributable to infectious diseases (68\% to AIDS, $2 \%$ to other infectious diseases), while low proportions of deaths were due to neoplasms (10\%) and diseases of the circulatory system (4\%). This pattern strongly diverged from the one observed among non-AIDS/HIV deaths. Considering MCOD data (Fig. 1b), the more frequently mentioned causes in the death certificates of PWA were infectious diseases other than AIDS (52\%), symptoms-signs and ill-defined diseases (41\%), diseases of digestive (36\%), respiratory (33\%), and circulatory (32\%) systems, and neoplasms (29\%). The most frequently reported conditions in the comparison group were neoplasms and diseases of the circulatory system, mentioned in $47 \%$ and $46 \%$ of the certificates, respectively.

Table 1 shows crude proportions of certificates mentioning specific causes among AIDS and non-AIDS/HIV deaths and statistically significant values of ASPR with 95\% CI.

The analysis highlighted, as expected, high values of the ASPR for all the AIDS-defining conditions, which are rare among non-AIDS/HIV deaths. The condition most strongly associated with AIDS was toxoplasmosis (ASPR $=4,167 ; 95 \%$ CI: 583.4-29,769.1), in addition to other AIDS-defining infections such as criptococcosis (ASPR $=480.4 ; 95 \%$ CI: 192.1-1,201.2), other mycobacterial infections (other than tuberculosis and Hansen disease; ASPR $=330.3 ; 95 \% \mathrm{CI}:$ 157.4-693) and pneumocystosis (ASPR $=208.1$; 95\% CI: 129.6-334.2). Besides infectious diseases, a very strong association was observed for Kaposi sarcoma (KS; ASPR = 298.9; 95\% CI: 162.4-550.1) and -although with lower ASPR 


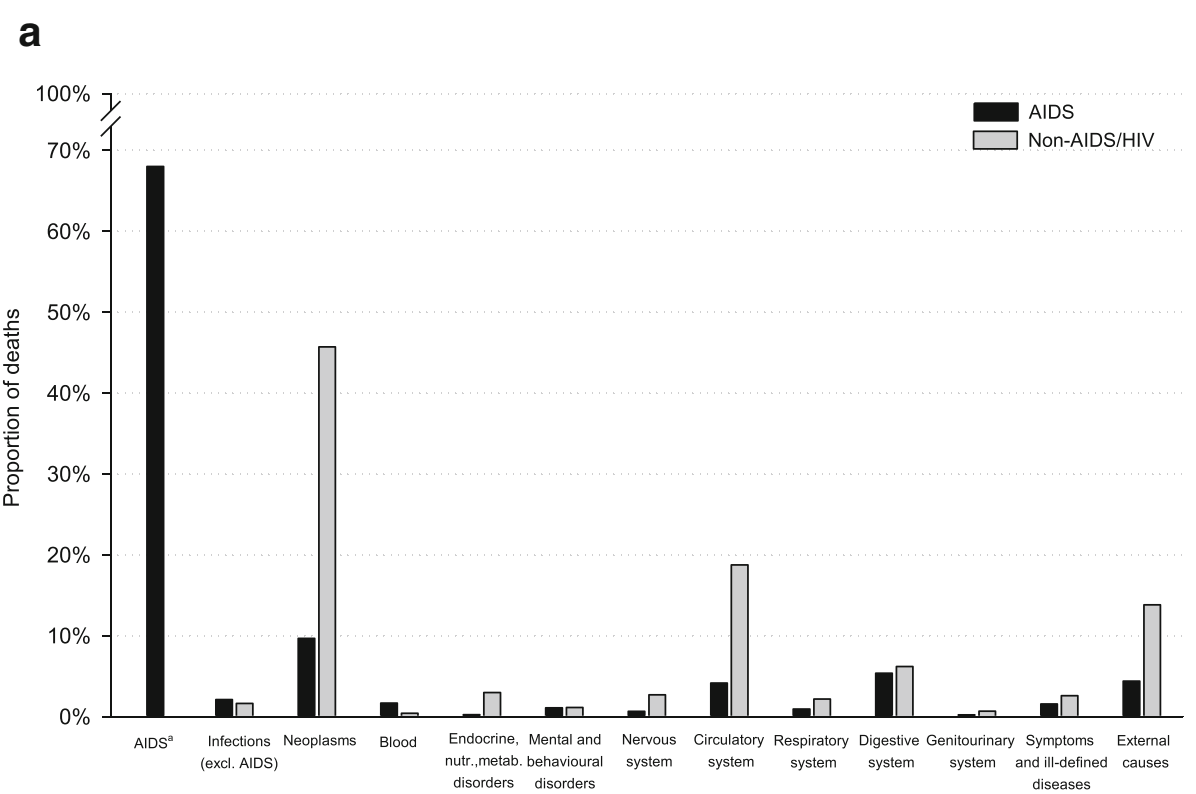

b

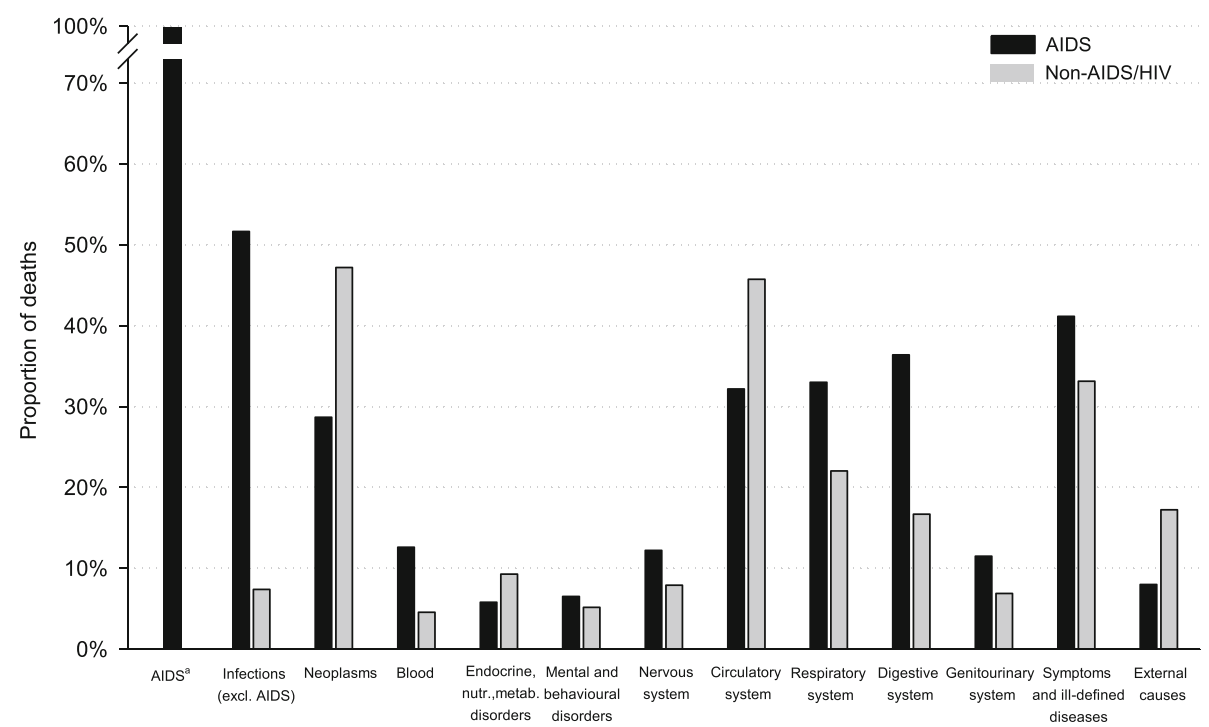

Fig. 1 Underlying cause (a) and multiple cause (b)of death distribution: a comparison between AIDS deaths and non-AIDS/HIV deaths. Italy, period 20062010. a ICD-10 codes B20-B24. In the representation of multiple causes for AIDS deaths, all the 2,515 certificates matched to the RAIDS are assumed to mention a B20-B24 code

values compared to $\mathrm{KS}$ - diffuse and other/unspecified non-Hodgkin lymphoma (NHL; ASPR $=14.1$ and 6.5, respectively), cachexia $(\mathrm{ASPR}=3.9)$, and cervical cancer $(\mathrm{ASPR}=2.8)$.

Among non AIDS-defining diseases, the infectious conditions with the highest ASPR were leishmaniasis (ASPR $=188 ; 95 \%$ CI: 39.5-894.1) and chronic viral hepatitis $(\mathrm{ASPR}=13.1 ; 95 \%$ CI: 12.1-14.2). This latter condition was reported in $23.9 \%$ of AIDS deaths (600 cases; of these, 586 reported hepatitis $C$ virus) versus
$1.8 \%$ in the comparison group. High values of ASPR were also observed for chronic hepatitis not stated as viral (11.0; 95\% CI: 8.2-14.7). ASPR was also high for encephalitis, myelitis and encephalomyelitis (14.3; 95\% CI: $10.6-19.1)$ and unspecified dementia (13.1; $95 \%$ CI: 8.3-20.5).

Among non-AIDS defining cancers, only anal $(\mathrm{ASPR}=12.1 ; 95 \% \mathrm{CI}: 7.7-18.8)$ and liver $(\mathrm{ASPR}=1.9$; 95\% CI: 1.6-2.3) showed values of ASPR significantly higher than unity. Regarding the entire group of 
Table 1 Multiple cause of death analysis, comparing certificates of AIDS deaths and non-AIDS/HIV deaths: crude proportions of deaths and age-standardized proportion ratio (ASPR) ${ }^{\S}$, with corresponding 95\% confidence intervals (CI), by any mentioned cause of death

\begin{tabular}{|c|c|c|c|c|c|}
\hline \multicolumn{2}{|c|}{ Cause of death mentioned in the death certificate } & \multicolumn{2}{|c|}{ Crude proportion (\%) } & \multirow[t]{2}{*}{ ASPR } & \multirow[t]{2}{*}{$95 \% \mathrm{Cl}$} \\
\hline ICD-10 code & Description & $\begin{array}{l}\text { AIDS deaths } \\
\text { (Total no. } 2,515 \text { ) }\end{array}$ & $\begin{array}{l}\text { Non-AIDS/HIV deaths } \\
\text { (Total no. 123,224) }\end{array}$ & & \\
\hline$\overline{A 00-B 99}$ & Infectious and parasitic diseases (excluding B20-B24) & 51.7 & 7.4 & 7.0 & $(6.7-7.3)$ \\
\hline B58 & Toxoplasmosis & 3.3 & $<0.1$ & 4167.4 & $(583.4-29,769.1)$ \\
\hline B45 & Criptococcosis & 1.8 & $<0.1$ & 480.4 & $(192.1-1,201.2)$ \\
\hline A31 & Infection due to other mycobacteria & 2.1 & $<0.1$ & 330.3 & $(157.4-693.0)$ \\
\hline B59 & Pneumocystosis & 3.1 & $<0.1$ & 208.1 & $(129.6-334.2)$ \\
\hline B55 & Leishmaniasis & 0.4 & $<0.1$ & 188.0 & $(39.5-894.1)$ \\
\hline A81 & Atypical virus infections of central nervous system & 2.7 & $<0.1$ & 63.6 & $(44.4-91.1)$ \\
\hline B25 & Cytomegaloviral disease & 4.8 & 0.1 & 62.9 & $(48.7-81.4)$ \\
\hline B37 & Candidiasis & 4.0 & 0.1 & 50.1 & $(37.7-66.5)$ \\
\hline A16 & $\begin{array}{l}\text { Respiratory tuberculosis. not confirmed bacteriologically } \\
\text { or histologically }\end{array}$ & 1.2 & 0.1 & 15.6 & $(10.5-23.1)$ \\
\hline B18 & Chronic viral hepatitis & 23.9 & 1.8 & 13.1 & $(12.1-14.2)$ \\
\hline A49 & Bacterial infection of unspecified site & 0.5 & 0.1 & 8.2 & $(4.3-15.8)$ \\
\hline B44 & Aspergillosis & 0.4 & 0.1 & 6.5 & $(3.7-11.6)$ \\
\hline B16 & Acute hepatitis B & 1.4 & 0.2 & 5.9 & $(4.1-8.5)$ \\
\hline A41 & Other septicemia & 12.2 & 4.7 & 2.6 & $(2.4-2.9)$ \\
\hline C00-D48 & Neoplasms ${ }^{a}$ & 28.7 & 47.2 & 0.6 & $(0.6-0.7)$ \\
\hline C46 & Kaposi's sarcoma & 2.7 & $<0.1$ & 298.9 & $(162.4-550.1)$ \\
\hline $\mathrm{C} 83$ & Diffuse non-Hodgkin's lymphoma & 2.0 & 0.1 & 14.1 & $(10.2-19.4)$ \\
\hline $\mathrm{C} 21$ & Malignant neoplasm of anus and anal canal & 1.0 & 0.1 & 12.1 & $(7.7-18.8)$ \\
\hline $\mathrm{C} 85$ & Other and unspecified types of non-Hodgkin's lymphoma & 8.4 & 1.3 & 6.5 & $(5.7-7.5)$ \\
\hline C81 & Hodgkin's disease & 1.0 & 0.3 & 3.1 & $(2.1-4.5)$ \\
\hline $\mathrm{C} 53$ & Malignant neoplasm of cervix uterib & 3.9 & 1.1 & 2.8 & $(1.7-4.6)$ \\
\hline $\mathrm{C} 22$ & Malignant neoplasm of liver and intrahepatic bile ducts & 3.3 & 2.0 & 1.9 & $(1.6-2.3)$ \\
\hline C34 & Malignant neoplasm of bronchus and lung & 2.9 & 7.9 & 0.4 & $(0.3-0.5)$ \\
\hline $\mathrm{C} 25$ & Malignant neoplasm of pancreas & 0.4 & 2.3 & 0.2 & $(0.1-0.4)$ \\
\hline D50-D89 & Diseases of the blood. immunological disorderss ${ }^{a}$ & 12.6 & 4.5 & 2.8 & $(2.5-3.1)$ \\
\hline D61 & Other aplastic anemias & 2.5 & 0.5 & 5.1 & $(4.0-6.5)$ \\
\hline D70 & Agranulocytosis & 0.6 & 0.2 & 2.7 & $(1.6-4.6)$ \\
\hline D69 & Purpura and other hemorrhagic conditions & 1.1 & 0.6 & 2.0 & $(1.4-2.8)$ \\
\hline E00-E90 & Endocrine. nutritional metabolic diseases ${ }^{a}$ & 2.5 & 4.8 & 0.6 & $(0.4-0.7)$ \\
\hline E14 & Unspecified diabetes mellitus & 1.7 & 3.8 & 0.5 & $(0.4-0.7)$ \\
\hline F01-F99 & Mental and behavioral disorders ${ }^{a}$ & 6.5 & 5.2 & 1.2 & $(1.0-1.4)$ \\
\hline F03 & Unspecified dementia & 1.0 & 0.1 & 13.1 & $(8.3-20.5)$ \\
\hline F11 & Mental and behavioral disorders due to use of opioids & 0.7 & 0.2 & 4.2 & $(2.5-7.0)$ \\
\hline F19 & $\begin{array}{l}\text { Mental and behavioral disorders due to multiple drug } \\
\text { use and use of other psychoactive substances }\end{array}$ & 2.7 & 0.7 & 3.4 & $(2.6-4.4)$ \\
\hline F09 & Unspecified organic or symptomatic mental disorder & 0.4 & 0.2 & 2.0 & $(1.1-3.9)$ \\
\hline F10 & Mental and behavioral disorders due to use of alcohol & 1.1 & 1.3 & 0.6 & $(0.4-1.0)$ \\
\hline F32 & Depressive episode & 0.4 & 1.0 & 0.5 & $(0.3-0.8)$ \\
\hline G00-H95 & Diseases of the nervous system and the sense organs ${ }^{a}$ & 12.2 & 7.9 & 1.5 & $(1.4-1.7)$ \\
\hline G04 & Encephalitis. myelitis and encephalomyelitis & 2.3 & 0.2 & 14.3 & $(10.6-19.1)$ \\
\hline
\end{tabular}


Table 1 Multiple cause of death analysis, comparing certificates of AIDS deaths and non-AIDS/HIV deaths: crude proportions of deaths and age-standardized proportion ratio (ASPR) ${ }^{\S}$, with corresponding 95\% confidence intervals (Cl), by any mentioned cause of death (Continued)

\begin{tabular}{|c|c|c|c|c|c|}
\hline G93 & Other disorders of brain & 6.4 & 2.8 & 2.4 & $(2.1-2.8)$ \\
\hline G31 & $\begin{array}{l}\text { Other degenerative diseases of nervous system. not } \\
\text { elsewhere classified }\end{array}$ & 0.4 & 0.2 & 2.4 & $(1.4-4.2)$ \\
\hline G62 & Other polyneuropathies & 0.4 & 0.2 & 2.2 & $(1.1-4.4)$ \\
\hline 100-199 & Diseases of the circulatory system ${ }^{a}$ & 32.2 & 45.7 & 0.7 & $(0.7-0.7)$ \\
\hline 133 & Acute and subacute endocarditis & 0.4 & 0.1 & 2.8 & $(1.5-5.4)$ \\
\hline 127 & Other pulmonary heart diseases & 1.2 & 0.4 & 2.5 & $(1.7-3.7)$ \\
\hline 151 & Complications and ill-defined descriptions of heart disease & 4.1 & 5.4 & 0.7 & $(0.6-0.9)$ \\
\hline 150 & Heart failure & 2.9 & 3.9 & 0.7 & $(0.6-0.9)$ \\
\hline 161 & Intracerebral hemorrhage & 1.8 & 2.9 & 0.7 & $(0.5-0.9)$ \\
\hline | 25 & Chronic ischemic heart disease & 1.9 & 4.7 & 0.5 & $(0.4-0.6)$ \\
\hline 126 & Pulmonary embolism & 0.7 & 1.5 & 0.4 & $(0.3-0.7)$ \\
\hline 164 & Stroke. not specified as hemorrhage or infarction & 0.4 & 1.1 & 0.3 & $(0.2-0.7)$ \\
\hline 121 & Acute myocardial infarction & 2.1 & 7.5 & 0.3 & $(0.2-0.4)$ \\
\hline | 49 & Other cardiac arrhythmias & 0.4 & 1.9 & 0.3 & $(0.2-0.5)$ \\
\hline 110 & Essential (primary) hypertension & 1.1 & 4.9 & 0.3 & $(0.2-0.4)$ \\
\hline J00- $/ 99$ & Diseases of the respiratory system ${ }^{a}$ & 33.0 & 22.0 & 1.5 & $(1.5-1.6)$ \\
\hline J84 & Other interstitial pulmonary diseases & 2.7 & 0.5 & 6.2 & $(4.9-7.9)$ \\
\hline J93 & Pneumothorax & 0.8 & 0.1 & 6.1 & $(3.9-9.6)$ \\
\hline J15 & Bacterial pneumonia. not elsewhere classified & 0.5 & 0.1 & 6.0 & $(3.3-11)$ \\
\hline J18 & Pneumonia. organism unspecified & 14.2 & 3.3 & 4.4 & $(4.0-4.9)$ \\
\hline J80 & Adult respiratory distress syndrome & 1.0 & 0.4 & 2.5 & $(1.7-3.8)$ \\
\hline$J 69$ & Pneumonitis due to solids and liquids & 0.5 & 0.3 & 2.0 & $(1.2-3.4)$ \\
\hline$J 44$ & Other chronic obstructive pulmonary disease & 1.4 & 1.2 & 1.5 & $(1.1-2.0)$ \\
\hline J96 & Respiratory failure. not elsewhere classified & 14.0 & 12.3 & 1.2 & $(1.0-1.3)$ \\
\hline J81 & Pulmonary edema & 3.4 & 4.6 & 0.7 & $(0.6-0.9)$ \\
\hline K00-K92 & Diseases of the digestive system ${ }^{a}$ & 36.4 & 16.7 & 2.2 & $(2.1-2.3)$ \\
\hline K73 & Chronic hepatitis. not elsewhere classified & 2.5 & 0.2 & 11.0 & $(8.2-14.7)$ \\
\hline K52 & Other non-infective gastroenteritis and colitis & 0.8 & 0.1 & 6.4 & $(4.1-9.8)$ \\
\hline K74 & Fibrosis and cirrhosis of liver & 24.3 & 5.6 & 4.4 & $(4.1-4.7)$ \\
\hline K85 & Acute pancreatitis & 1.0 & 0.4 & 2.5 & $(1.7-3.8)$ \\
\hline K76 & Other diseases of liver & 6.5 & 3.0 & 2.2 & $(1.9-2.6)$ \\
\hline K72 & Hepatic failure. not elsewhere classified & 11.3 & 5.6 & 1.9 & $(1.7-2.1)$ \\
\hline K70 & Alcoholic liver disease & 1.0 & 1.8 & 0.6 & $(0.4-0.9)$ \\
\hline K56 & Paralytic ileus and intestinal obstruction without hernia & 0.8 & 1.4 & 0.6 & $(0.4-0.9)$ \\
\hline NOO-N99 & Diseases of the genitourinary system ${ }^{a}$ & 11.5 & 6.9 & 1.7 & $(1.5-1.9)$ \\
\hline N17 & Acute renal failure & 3.7 & 1.7 & 2.4 & $(2.0-2.9)$ \\
\hline N19 & Unspecified renal failure & 4.9 & 3.3 & 1.5 & $(1.3-1.8)$ \\
\hline Ro0-R99 & Symptoms signs and ill-defined causes (excluding R75) ${ }^{\mathrm{a}}$ & 41.2 & 33.1 & 1.2 & $(1.2-1.3)$ \\
\hline R16 & Hepatomegaly and splenomegaly. not elsewhere classified & 0.4 & 0.1 & 5.1 & $(3.0-9.0)$ \\
\hline R64 & Cachexia & 16.0 & 4.2 & 3.9 & $(3.6-4.3)$ \\
\hline R91 & Abnormal findings on diagnostic imaging of lung & 0.4 & 0.2 & 2.3 & $(1.3-4.0)$ \\
\hline R57 & Shock. not elsewhere classified & 8.6 & 10.1 & 0.8 & $(0.7-1.0)$ \\
\hline R40 & Somnolence. stupor and coma & 3.2 & 4.5 & 0.7 & $(0.6-0.9)$ \\
\hline
\end{tabular}


Table 1 Multiple cause of death analysis, comparing certificates of AIDS deaths and non-AIDS/HIV deaths: crude proportions of deaths and age-standardized proportion ratio (ASPR) ${ }^{5}$, with corresponding 95\% confidence intervals (CI), by any mentioned cause of death (Continued)

\begin{tabular}{|c|c|c|c|c|c|}
\hline V00-Y99 & External causes of death ${ }^{a}$ & 8.0 & 17.2 & 0.4 & $(0.4-0.5)$ \\
\hline$X 42$ & $\begin{array}{l}\text { Accidental poisoning by and exposure to narcotics } \\
\text { and psychodysleptics [hallucinogens] not elsewhere } \\
\text { classified }\end{array}$ & 1.0 & 0.3 & 2.6 & $(1.7-4.0)$ \\
\hline$\times 59$ & Exposure to unspecified factor & 0.5 & 0.8 & 0.5 & $(0.3-0.9)$ \\
\hline V89 & $\begin{array}{l}\text { Motor- or non motor-vehicle accident type of } \\
\text { vehicle unspecified }\end{array}$ & 0.4 & 2.7 & 0.1 & $(0.1-0.3)$ \\
\hline
\end{tabular}

Deaths of people aged 35-54 years. Italy, 2006-2010

${ }^{\S}$ Calculated as the age-standardized ratio between the proportion of deaths reporting a selected cause among AIDS deaths and the same proportion among non-AIDS/HIV deaths

aICD-10 chapter. The values of the proportion for the specific ICD-10 categories do not sum up to the totals by ICD-10 chapter because 1 ) only causes of death with a statistically significant ASPR and with at least 10 cases among AIDS deaths are shown and 2) each death certificate could report more than one cause within the same ICD-10 chapter

bonly females

neoplasms, instead, the analysis showed a highest frequency among non-AIDS/HIV deaths (ASPR =0.6; 95\% CI: 0.6-0.7), as for two major cancer sites, i.e. lung (ASPR $=0.4 ; 95 \%$ CI: $0.3-0.5)$ and pancreas $($ ASPR $=0.2 ; 95 \%$ CI: 0.1-0.4).

Other cancer sites very frequently reported in the 3554-year age group of the general population but poorly mentioned in AIDS deaths (less than 10 cases, and therefore not shown in Table 1) were female breast (19.3\% in non-AIDS/HIV women and $0.9 \%$ in AIDS ones) (ASPR = 0.03 ; 95\% CI: $0.01-0.09)$, colon $(\mathrm{ASPR}=0.1 ; 95 \% \mathrm{CI}$ : $0.03-0.16$ ), stomach (ASPR $=0.1 ; 95 \%$ CI: $0.1-0.2$ ), and brain (ASPR $=0.04 ; 95 \%$ CI: 0.01-0.15) cancers.

Moreover, the analysis highlighted some conditions very frequently reported among AIDS deaths, but with relatively low values of ASPR, particularly fibrosis/cirrhosis and hepatic failure (mentioned in the $24.3 \%$ and $11.3 \%$ of certificates of AIDS deaths, respectively; ASPR $=4.4 ; 95 \%$ CI: $4.1-4.7$ and ASPR $=1.9 ; 95 \%$ CI: $1.7-2.1$, respectively) and pneumonia (proportion among AIDS deaths 14.2\%; ASPR $=4.4,95 \%$ CI: 4.1-4.9).

Also, mental and behavioral disorders due to psychoactive drugs and renal failure resulted significantly more frequent among AIDS deaths.

Concerning circulatory system diseases, only acute and subacute endocarditis (ASPR $=2.8 ; 95 \%$ CI: $1.5-5.4)$ and other pulmonary heart diseases $(\mathrm{ASPR}=2.5 ; 95 \% \mathrm{CI}$ : 1.7-3.7) were significantly associated.

Unspecified diabetes mellitus was less frequently mentioned in AIDS deaths than in non-AIDS/HIV deaths (ASPR $=0.5$; 95\% CI: 0.4-0.7).

Among AIDS deaths, a lower frequency of external causes was observed (ASPR $=0.4 ; 95 \%$ CI: 0.4-0.5), but a significantly higher association for accidental poisoning by narcotics and psychodysleptics [hallucinogens] emerged $(\mathrm{ASPR}=2.6 ; 95 \%$ CI: 1.7-4.0). Suicide by hanging - frequently mentioned among non-AIDS/HIV (proportion $=2.4 \%)-$ showed a low value of the ASPR (0.2; 95\% CI: 0.1-0.3, data not shown).

\section{Discussion}

This is the first time that MCOD data have been used to investigate cause-specific mortality of PWA in Italy, providing a detailed picture of the causes listed in their death certificates. The analysis of MCOD, compared to the use of UC data only, stressed the leading role of infectious diseases among the causes of death for AIDS patients, and it also showed the major contribution to death of other causes (e.g., diseases of digestive, respiratory, nervous, and genitourinary systems) that were more frequently mentioned in AIDS than in non-AIDS/ HIV death certificates. Moreover, although neoplasms and diseases of the circulatory system were not frequently the UC in PWA (10\% and 4\% of deaths, respectively), their contribution to death rose when MCOD were considered (respectively mentioned in $29 \%$ and $32 \%$ of AIDS deaths).

\section{Infectious and parasitic diseases}

Our results showed that although infectious diseases provided a small contribute to the UC among PWA, they represented the most common cause of death when considering the MCOD (Fig. 1); this result stressed the relevant role of these conditions (which are, in most cases, preventable or treatable) in the survival of HIVinfected individuals. The high proportion of infectious diseases among AIDS deaths has to be attributed in part to the immunodeficiency caused by HIV infection [21] and in part to behaviors that expose HIV-positive individuals to certain types of infections, such as viral hepatitis [22, 23]. In Italy, the HIV epidemic has been driven mainly by injecting drug users until a decade ago; some behaviors associated with drug use, such as alcohol abuse or non-sterile drug paraphernalia sharing, may 
have contributed to an increased risk of liver damage or parenteral acquisition of viral hepatitis infections $[6,15,24]$. Actually, chronic viral hepatitis was reported in about one-fourth of all death certificates of PWA. Of relevance, hepatitis $\mathrm{C}$ virus $(\mathrm{HCV})$ was the most frequent causative agent of chronic viral hepatitis deaths, underscoring the need of an early management of HIV$\mathrm{HCV}$ co-infected individuals [25].

Extremely high values of ASPR were observed for conditions included in the AIDS-defining disease list $[16,17]$ : toxoplasmosis, criptococcosis, infections due to other mycobacteria (other than tuberculosis and Hansen disease), pneumocystosis, cytomegaloviral disease, candidiasis, and respiratory tuberculosis. However, the contribution of each of these conditions was quite small in terms of proportion among infectious MCOD.

\section{Neoplasms}

Neoplasms, in particular AIDS-defining ones, are among the most common underlying causes of death among people with HIV infection or AIDS [6,8]. The use of MCOD, as compared to UC, clearly highlighted that the frequency of cancer diagnoses reported in the certificates of AIDS deaths is noteworthy (i.e., 29\%), and largely variable according to cancer sites/types. In addition to AIDS-defining cancers (i.e., KS, NHL, and cervical carcinoma), other cancers known to be frequently incident among HIV-infected people turned out to be frequently reported also in death certificates of PWA. The ASPR values for these cancers ranged from about 300 -fold for KS to about 2- or 3-fold for cervical carcinoma, Hodgkin lymphoma, anal, and liver carcinomas. Conversely, statistically significant reduced ASPR emerged for very common cancers in the general population (e.g., breast cancer in women, prostate cancer in men, colon-rectal, pancreatic cancers, and lung cancer). Findings regarding lung cancer, in particular, were apparently in contrast with the literature, since people with HIV/AIDS consistently reported higher incidence of lung cancer in Italy and elsewhere [26, 27]. Furthermore, in a previous UC analysis among Italian PWA, a 6.6-fold elevated risk of death for non-AIDS defining cancers was documented as compared to the general population, including a 5.9fold higher death risk for lung cancer [28]. Nevertheless, the MCOD analysis allowed to explore the frequency of non-AIDS defining cancers when they were not UC. These findings underlined that a direct comparison of our findings - obtained by means of MCOD approach with those from previous studies based on the risk of dying for specific UC may be misleading $[6,8]$. The results of our analysis seemed thus to stress the strong overall burden of cancer among the causes of death, pointing to the importance of cancer prevention in people with HIV infection and AIDS to enhance their life expectancy.

\section{Diseases of the blood and immunological disorders}

Overall, 13\% of death certificates of deceased PWA reported one or more diseases of the blood and/or immunological disorders - a proportion that was 3-fold higher than among deceased people without AIDS/HIV. Notably, anaplastic and hemorrhagic conditions turned out to be associated with highly positive ASPR, a potentially surrogate marker of HIV-immunosuppression. Although a comparison with similar investigations is made difficult, it seems that our findings are in agreement with the existing evidence indicating that anemia is a frequent complication of HIV infection associated with an elevated risk of death [29].

\section{Endocrine, nutritional metabolic diseases}

A negative association between unspecified diabetes mellitus and AIDS was found, due to a double proportion of this disease among non-AIDS deaths compared to AIDS deaths. The proportion of diabetes mellitus reported among non-AIDS deaths was consistent with the results from the PASSI Italian Surveillance System [30], suggesting that this condition could be underreported among AIDS deaths because deemed not relevant to death. Despite the high association reported in the literature between diabetes and HAART therapy [31], the low ASPR found for diabetes among AIDS deaths could also be due to a to a large number of late presenters without therapy.

\section{Mental and behavioral disorders}

The proportion of mental and behavioral disorders resulted similar between the two study groups, although a high value of ASPR for dementia was observed. Dementia is commonly associated to AIDS. It could be caused by specific characteristics of HIV that reaches the central nervous system, immediately after primary infection, and plays a central role in determining pathological alterations and neurocognitive deficits [32]. The prevalence of neurocognitive disorders associated to HIV remains high in the HIV population even in the HAART era, due primarily to the persistence, even among treated patient, of forms of HIV associated neurocognitive disorders (HAND) [33]. European data confirm the high prevalence of HAND in HIV treated population, which amounts to $69 \%$ of the HIV-positive population with suppression plasma viremia [34].

Mental and behavioral disorders due to psychoactive drugs also resulted highly associated with AIDS: historically, injecting drug users are indeed the first Italian group which acquired the HIV infection [17]. 


\section{Diseases of the nervous system}

Among diseases of the nervous system, the highest value of the ASPR corresponded to encephalitis, myelitis and encephalomyelitis, indicating that these causes are about 14-fold more frequent in AIDS deaths than in nonAIDS/HIV deaths [35]. These conditions could be a consequence to many infectious AIDS related diseases such as herpes simplex virus, cytomegalovirus, and toxoplasmosis [16]. Furthermore, recent studies showed that HIV can cause direct damage to the brain [36].

\section{Diseases of the circulatory system}

Diseases of the circulatory system were more frequently reported among non-AIDS/HIV deaths than among AIDS deaths. However, they were mentioned in about $32 \%$ of death certificates of PWA. This remarkable proportion is consistent with the role of circulatory system diseases (especially cardiovascular diseases) as causes of death in people with AIDS or HIV infection described in previous studies $[5,6]$.

The only two diseases with a higher frequency among AIDS deaths, i.e., acute and subacute endocarditis and other pulmonary heart diseases, are very common cardiac complications due to injecting drug use [37].

Values of ASPR for ischemic heart diseases and heart failure, in both cases lower than unity, are in agreement with the results obtained by Whiteside and colleagues (2015) in comparing mortality rates of people with HIV infection to those of the general population in the US, by means of MCOD data.

\section{Diseases of the respiratory system}

With regard to the frequency of respiratory conditions, it is worth noting that one out of three AIDS deaths had a respiratory disease listed in the death certificate - a frequency magnitude concealed when the UC approach is used. Pneumonia (organism unspecified) wasthe most common listed respiratory condition, in agreement with what was observed by Schwarz (2014) in the same period.

\section{Diseases of the digestive system}

Hepatic diseases accounted for the largest proportion of causes of death and showed significantly high proportions among AIDS deaths. Liver diseases are one of the most frequent non-AIDS-defining causes of death in people living with HIV for a number of reasons: the high prevalence of hepatotropic viral co-infections, the hepatotoxicity of antiretroviral drugs, and the emergence of new liver conditions, including non-alcoholic fatty liver disease and non-cirrhotic portal hypertension [38]. Considering the high association between HIV and hepatic viral infections [39], it can be hypothesized that death certificates reporting chronic viral hepatitis in the group of infectious diseases would also frequently report a liver-associated condition coded in the group of diseases of the digestive system. The contribution of concurrent liver-related causes of death would suggest that hepatic viral co-infections and chronic liver damage also constitute a relevant cause of death among Italian PWA.

\section{Diseases of the genitourinary system}

Genitourinary diseases were rarely mentioned as UC, but they appeared to be listed in about $11 \%$ of death certificates of PWA when the MCOD approach was used. Our finding is in agreement with previous evidence showing that up to $3 \%$ of HIV-infected patients may suffer of chronic kidney diseases in the HAART era [40]. The MCOD approach seems, thus, to offer an important opportunity to quantify the prevalence of renal failure, in particular, and to stress the importance of screening for renal disorders as a clinical challenge in the management of people with HIV/AIDS. Furthermore, genitourinary diseases were more frequently mentioned in the death certificates of PWA than among those of nonAIDS/HIV people, in agreement with other studies showing that people with AIDS or HIV infection are at higher risk of death for renal diseases $[6,15]$.

\section{Symptoms, signs, and ill-defined causes}

Symptoms, signs, and ill-defined causes were reported in about $40 \%$ of certificates for AIDS deaths: the condition most frequently mentioned was cachexia, typically linked to the wasting syndrome, as reported in other international studies on AIDS deaths [41].

\section{External causes}

Among external causes of deaths, only "accidental poisoning by and exposure to narcotics psychodysleptics" showed positive association with AIDS due to overdose among injecting drug users, that constituted the majority of Italian AIDS cases reported from the beginning of the epidemic [17].

The main strengths of this study were the national coverage of the population-based registries used to identify people with and without AIDS, the AIDS case definition based on official diagnoses mandatorily reported to the RAIDS, and the use of MCOD data.

The exclusion from the analysis of death certificates from the Trento and Bolzano provinces is expected to not affect the results, since the number of cases from these areas is expected to be very small (overall UC deaths due to AIDS account for $0.8 \%$ of UC deaths due to AIDS in Italy in the period 2006-2010).

The choice to focus on deaths aged 35-54 years enabled feasible (robust) MCOD analysis by detailed cause-ofdeath category. Furthermore, it prevented possible bias due to misdiagnosis of HIV/AIDS in people at older ages, 
which could result in undiagnosed AIDS cases among the comparison group. However, future developments of the study will include the analysis of deaths of PWA aged 55 years and over, in order to investigate also the mortality pattern of older AIDS patients.

A quota of death certificates were not matched to the RAIDS mentioned codes B20-B24 or R75 $(1,905)$ and were then excluded from the comparison group. These cases are currently under investigation to establish how many of them referred to AIDS deaths or, more plausibly, to deaths of people reported with HIV infection. This in-depth analysis requires to take into account both multiple cause codes and the text reported by the certifier.

Only a really small number of death certificates of PWA reported codes B20-B24 or R75 as single cause of death (8 out of 2,515$)$, without any impact on the validity of MCOD analysis.

The ASPR compares proportions of deaths and needs only mortality data without the risk exposed population. The indicator highlights the conditions most frequently mentioned in AIDS versus non-AIDS/HIV deaths. Therefore, the ASPR does not measure the overall mortality risk of PWA compared to the general population, as in other analyses [15]. Briefly, it is a measure of the propensity of a condition to act as a cause of death in AIDS patients. In addition, it is useful in detecting the conditions reported in the chain of events leading to death.

It is well known that mortality data derived from death certificates have some limitations. Among these, the death certificate completion is entrusted to the medical knowledge of the certifying physician, and it can suffer from a lack of specificity and/or underreporting [42]. On the other hand, the death certificates are the most relevant tool for understanding which causes of death are the most prevalent in a given population, and this information is central to resource allocation for prevention and treatment.

\section{Conclusions}

The present study is the first application of MCOD analysis to PWA in Italy. This approach, based on all the conditions that were directly responsible for the death or may have contributed to it, allowed identifying the circumstances leading PWA to death in a more comprehensive picture compared to the traditional UC analysis. From a public health perspective, interventions targeted at preventing all causes of death beside the UC can lead to both improvements in the health status and mortality reductions for a given population. Indeed, many of the contributing causes the MCOD approach allowed to focus on, are consequences or complications of the UC (or its therapy) to which tertiary prevention is typically addressed (for instance cardiovascular diseases as consequence of HAART therapy). Study findings could be of aid in planning public health interventions oriented to the prevention of death among PWA in the late HAART era, by directing the attention to the role of non-AIDS-defining conditions.

\section{Abbreviations \\ ASPR: Age-standardized proportion ratio; Cl: Confidence Interval; HAART: Highly active antiretroviral therapy; HCV: Hepatitis C virus; ICD- 10: International classification of diseases), $10^{\text {th }}$ revision; ISS: National Institute of Health; ISTAT: Italian National Institute of Statistics; KS: Kaposi sarcoma; MCOD: Multiple cause of death; NHL: Non-Hodgkin lymphoma; PWA: People with AIDS; RAIDS: Italian National AIDS Registry; RCOD: National register of causes of death; UC: Underlying cause of death; WHO: World Health Organization}

\section{Acknowledgements}

The authors wish to thank Mrs. Luigina Mei for editorial assistance, Mrs. Lucia Pugliese and Mr. Stefano Boros for data input and management of the Italian National AIDS Registry.

\section{Funding}

This research project was supported by the Italian Ministry of Health (Fondi Ricerca Corrente "IRCCS, Centro di Riferimento Oncologico, Aviano"). The funding body had no role in the study design, data collection, analysis, interpretation, or manuscript writing.

\section{Availability of data and materials}

Information on data used in this study is available through the corresponding author.

\section{Authors' contributions}

EG, FG, MP, LF designed the study, managed the mortality databases and drafted the article; EG, FG performed the statistical analysis; AZ, SV, MT participated in the design of the study, conducted the record linkage and revised the article; DS coordinated the study group, participated in the design of the study, contributed to data interpretation and revised the article; BS participated in the design of the study, contributed to data interpretation and revised the article; VR, LC participated in the design of the study, managed the AIDS database and revised the article. All authors contributed to final manuscript drafting and approved the final version.

\section{Competing interests}

The authors declare that they have no conflict of interest.

\section{Consent for publication}

Not applicable.

\section{Ethics approval and consent to participate}

The study was carried out in compliance with the national law regulating the use of data from people with AIDS and according to the authorization of the Italian Data Protection Authority (provided in the National Statistical Plan).

\section{Publisher's Note}

Springer Nature remains neutral with regard to jurisdictional claims in published maps and institutional affiliations.

\section{Author details}

${ }^{1}$ Servizio Sistema integrato salute, assistenza, previdenza e giustizia, Istituto Nazionale di Statistica, Viale Liegi 13, 00198 Rome, Italy. ${ }^{2}$ Unit of Cancer Epidemiology, CRO Aviano National Cancer Institute, Via Gallini 2, 33081 Aviano, PN, Italy. ${ }^{3}$ Centro Operativo AIDS, Istituto Superiore di Sanità, Viale Regina Elena 299, 00161 Rome, Italy. 
Received: 16 June 2016 Accepted: 4 May 2017 Published online: 18 May 2017

\section{References}

1. Raimondo M, Boros S, Regine V, Pugliese L, Santaquilani M, Ferri M, et al. Aggiornamento delle nuove diagnosi di infezione da HIV e dei casi di AIDS in Italia al 31 dicembre 2015. Not Ist Super Sanità. 2016;29 Suppl 1:9.

2. Camoni L, Regine V, Stanecki K, Salfa MC, Raimondo M, Suligoi B. Estimates of the number of people living with HIV in Italy. Biomed Res Int. 2014;2014: 209619. doi:10.1155/2014/209619.

3. Camoni L, Raimondo M, Dorrucci M, Regine V, Salfa MC, Suligoi B, CARPHA Study Group. Estimating minimum adult HIV prevalence: a cross-sectional study to assess the characteristics of people living with HIV in Italy. AIDS Res Hum Retroviruses. 2015;31(3):282-7. doi:10.1089/AID.2014.0154.

4. Antiretroviral Therapy Cohort Collaboration. Life expectancy of individuals on combination antiretroviral therapy in high-income countries: a collaborative analysis of 14 cohort studies. Lancet. 2008;372:293-9.

5. Palella Jr FJ, Baker RK, Moorman AC, Chmiel JS, Wood KC, Brooks JT, Holmberg SD. Mortality in the highly active antiretroviral therapy era: Changing causes of death and disease in the HIV Outpatient Study. J Acquir Immune Defic Syndr. 2006;43:27-34

6. Schwarcz SK, Vu A, Hsu LC, Hessol NA. Changes in causes of death among persons with AIDS: San Francisco, California, 1996-2011. AIDS Patient Care STDs. 2014;28(10):517-23. doi:10.1089/apc.2014.0079.

7. Smith CJ, Ryom L, Weber R, Morlat P, Pradier C, Reiss P, Kowalska JD, de Wit S, Law M, el Sadr W, Kirk O, Friis-Moller N, Monforte A, Phillips AN, Sabin CA Lundgren JD D, A:D Study Group. Trends in underlying causes of death in people with HIV from 1999 to 2011 (D:A:D): a multicohort collaboration. Lancet. 2014;384(9939):241-8. doi:10.1016/S0140-6736(14)60604-8.

8. Vandenhende MA, Roussillon C, Henard S, Morlat P, Oksenhendler E, Aumaitre H, Georget A, May T, Rosenthal E, Salmon D, Cacoub P, Costagliola D, Chêne G, Bonnet F; ANRS EN20 Mortalité 2010 study group. CancerRelated Causes of Death among HIV-Infected Patients in France in 2010: Evolution since 2000. PLoS One. 2015. doi: 10.1371/journal.pone.0129550.

9. World Health Organization. International statistical classification of diseases and related health problems. tenth revision (ICD-10). Geneva: WHO; 1992.

10. Chamblee RF, Evans MC. New dimensions in cause of death statistics. Am J Public Health. 1982;72(11):1265-70.

11. Romon I, Jougla E, Balkau B, Fagot Campagna A. The burden of diabetesrelated mortality in France in 2002: an analysis using both underlying and multiple causes of death. Eur J Epidemiol. 2008;23(5):327-34.

12. Désesquelles A, Demuru E, Salvatore MA, Pappagallo M, Frova L, Meslé F, Egidi V. Mortality from Alzheimer's disase, Parkinson's disease and dementia in France and Italy: a comparison using multiple-cause-of-death approach. J Aging Health. 2014;26(2):283-315

13. Redelings MD, Wise M, Sorvillo F. Using multiple cause-of-death data to investigate associations and causality between conditions listed on the death certificate. Am J Epidemiol. 2007;166(1):104-8.

14. Amey AKA, Forcheh N, Setlhare K. Multiple causes of death models for human immunodeficiency virus/acquired immune deficiency syndrome and related mortality in South Africa in 2006 and 2007. Open Access Med Stat. 2012;2:1-13

15. Whiteside YO, Selik R, An Q, Huang T, Karch D, Hernandez AL, Hall HI: Comparison of Rates of Death Having any Death-Certificate Mention of Heart, Kidney, or Liver Disease Among Persons Diagnosed with HIV Infection with those in the General US Population, 2009-2011. Open AIDS J 2015. doi:10.2174/1874613601509010014.

16. Ancelle Park RA. Expanded European AIDS cases definition (letter). Lancet. 1993;341(8842):441.

17. Camoni L, Boros $S$, Regine $V$, et al. Aggiornamento delle nuove diagnosi di infezione da HIV e dei casi di AIDS in Italia al 31 dicembre 2013. Not Ist Super Sanità. 2014;27 Suppl 1:9.

18. Conti S, Farchi G, Galletti A, Masocco M, Napoli PA, Pezzotti P, Rezza G, Toccaceli V, Cariani G. La notifica della mortalità per AIDS in Italia (1992): qualità della certificazione e sottostima. Giornale Italiano dell'AIDS. 1997:8(1):12-6.

19. Dal Maso L, Braga C, Franceschi S: Methodology Used for "Software for Automated Linkage in Italy" (SALI). J Biomed Inform 2001. doi:10.1006/ jbin.2002.1036.

20. Altman DG. Practical statistics for medical research. London: Chapman and Hall; 1991.
21. Djawe K, Buchacz K, Hsu L, Chen MJ, Selik RM, Rose C, Williams T, Brooks JT, Schwarcz S. Mortality risk after AIDS-defining opportunistic illness among HIV-infected persons-San Francisco, 1981-2012. J Infect Dis. 2015;212(9): 1366-75. doi:10.1093/infdis/jiv235.

22. Klein MB, Rollet-Kurhajec KC, Moodie EE, Yaphe S, Tyndall M, Walmsley S, Gill J, Martel-Laferriere V, Cooper C; Canadian Co-infection Cohort Investigators: Mortality in HIV-hepatitis C co-infected patients in Canada compared to the general Canadian population (2003-2013). AIDS 2014. doi:10.1097/QAD.0000000000000377.

23. Rosenthal E, Roussillon C, Salmon-Céron D, Georget A, Hénard S, Huleux T, Gueit I, Mortier E, Costagliola D, Morlat P, Chêne G, Cacoub P; Mortalité 2010 and GERMIVIC study groups: Liver-related deaths in HIV-infected patients between 1995 and 2010 in France: the Mortavic 2010 study in collaboration with the Agence Nationale de Recherche sur le SIDA (ANRS) EN 20 Mortalité 2010 survey. HIV Med 2015. doi:10.1111/hiv.12204

24. May MT, Justice AC, Birnie K, Ingle SM, Smit C, Smith C, Neau D, Guiguet M, Schwarze-Zander C, Moreno S, Guest JL, Monforte Ad, Tural C, Gill MJ, Bregenzer A, Kirk O, Saag M, Sterling TR, Crane HM, Sterne JA: Injection Drug Use and Hepatitis C as Risk Factors for Mortality in HIV-Infected Individuals: The Antiretroviral Therapy Cohort Collaboration J Acquir Immune Defic Syndr 2015. doi:10.1097/QAl.0000000000000603.

25. Norton B, Naggie S: The clinical management of HCV in the HIV-infected patient. Antivir Ther 2014. doi: 10.3851/IMP2910.

26. Shiels MS, Cole SR, Kirk GD, Poole C. A Meta-Analysis of the incidence of Non-AIDS cancer in HIV-Infected individuals. J Acquir Immune Defic Syndr. 2009;52:611-22.

27. Robbins HA, Pfeiffer RM, Shiels MS, Li J, Hall HI, Engels EA: Excess cancers among HIV-infected people in the United States. J Natl Cancer Inst 2015. doi:10.1093/jnci/dju503.

28. Zucchetto A, Suligoi B, De Paoli A, Pennazza S, Polesel J, Bruzzone S, Rezza G, De Paoli P, Dal Maso L, Serraino D. Excess mortality for NonAIDS defining cancers among People with AIDS. Clin Infect Dis. 2010; 51(9):1099-101.

29. Sullivan PS, Hanson DL, Chu SY, Jones JL, Ward JW. Epidemiology of anemia in human immunodeficiency virus (HIV)-infected persons: results from the multistate adult and adolescent spectrum of HIV disease surveillance project. Blood. 1998;91(1):301-8.

30. La sorveglianza Passi. I dati per I'Italia. http://www.epicentro.iss.it/passi/dati/ diabete.asp. [Accessed 09 May 2016].

31. Samaras K. Prevalence and pathogenesis of diabetes mellitus in HIV-1 infection treated with combined antiretroviral therapy. J Acquir Immune Defic Syndr. 2009;50(5):499-505. doi:10.1097/QAl.0b013e31819c291b.

32. Gonzalez-Scarano F, Martin-Garcia J. The neuropathogenesis of AIDS. Nat Rev Immunol. 2005;5:69-81.

33. Elbirt D, Mahlab-Guri K, Bezalel-Rosenberg S, Gill H, Attali M, Asher I. HIV-associated neurocognitive disorders (HAND). Isr Med Assoc J. 2015;17(1):54-9.

34. Baker LM, Paul RH, Heaps-Woodruff JM, Chang JY, Ortega M, Margolin Z, Usher C, Basco B, Cooley S, Ances BM: The Effect of Central Nervous System Penetration Effectiveness of Highly Active Antiretroviral Therapy on Neuropsychological Performance and Neuroimaging in HIV Infected Individuals. J Neuroimmune Pharmacol 2015. doi: 10.1007/s11481-015-9610-4.

35. Matinella A, Lanzafame M, Bonometti MA, Gajofatto A, Concia E, Vento S, Monaco S, Ferrari S: Neurological complications of HIV infection in pre-HAART and HAART era: a retrospective study. J Neurol 2015. doi:10.1007/s00415-015-7713-8.

36. Zenón F, Cantres-Rosario Y, Adiga R, Gonzalez M, Rodriguez-Franco E, Langford D, Melendez LM. HIV-infected microglia mediate cathepsin B-induced neurotoxicity. J Neurovirol. 2015;21(5):544-58. doi:10.1007/ s13365-015-0358-7.32.

37. Valencia E, Miró J. Endocarditis in the setting of HIV infection. AIDS ReV. 2004;6(2):97-106.

38. Joshi D, O'Grady J, Dieterich D, Gazzard B, Agarwal K. Increasing burden of liver disease in patients with HIV infection. Lancet. 2011:377(9772):1198-209.

39. Mallet $V$, Vallet-Pichard A, Pol S. The impact of human immunodeficiency virus on viral hepatitis. Liver Int. 2011:31 Suppl 1:135-9.

40. Colson AW, Florence E, Augustijn H, Verpooten GA, Lynen L, Gheuens E. Prevalence of chronic renal failure stage 3 or more in HIV-infected patients in Antwerp: an observational study. J Int AIDS Soc. 2010;13 Suppl 4:89. 
41. Lu TH, Chang HJ, Chen LS, Chu MH, Ou NM, Jen I. Changes in causes of death and associated conditions among persons with HIV/AIDS after the introduction of highly active antiretroviral therapy in Taiwan. J Formos Med Assoc. 2006:105(7):604-9.

42. Grippo F, Grande E, Pace M. Cause-of-death reporting: how to measure inaccurate completion. GENUS. 2013;69(3):25-45.

Submit your next manuscript to BioMed Central and we will help you at every step:

- We accept pre-submission inquiries

- Our selector tool helps you to find the most relevant journal

- We provide round the clock customer support

- Convenient online submission

- Thorough peer review

- Inclusion in PubMed and all major indexing services

- Maximum visibility for your research

Submit your manuscript at www.biomedcentral.com/submit 